\title{
Education for the Provision of Technologically Enhanced Legal Services
}

\author{
Václav Janeček, "Rebecca Williams ${ }^{\dagger}$ and Ewart Keep
}

\begin{abstract}
Legal professionals increasingly rely on digital technologies when they provide legal services. The most advanced technologies such as artificial intelligence (AI) promise great advancements of legal services, but lawyers are traditionally not educated in the field of digital technology and thus cannot fully unlock the potential of such technologies in their practice. In this paper, we identify five distinct skills and knowledge gaps that prevent lawyers from implementing AI and digital technology in the provision of legal services and suggest concrete models for education and training in this area. Our findings and recommendations are based on a series of semi-structured interviews, design and delivery of an experimental course in 'Law and Computer Science', and an analysis of the empirical data in view of wider debates in the literature concerning legal education and $21^{\text {st }}$ century skills.
\end{abstract}

Keywords: legal education, profession, digital technology, artificial intelligence, $21^{\text {st }}$ century skills, legal technologist

Acknowledgements: This research was supported by the UK Research and Innovation (UKRI) Industrial Strategy Challenge Fund: 'Next Generation Services'.

An early version of this paper was presented as part of a keynote talk at The Future of Legal Education and Training Conference 2020, organised by Legal Cheek, and the Future of LawTech Education (WP5) workshop organised by the University of Oxford as part of the AI4Law Workshop Series.

We would like to thank all our interviewees and the inaugural 'Law and Computer Science' class of 2019/20 for their insights. We would also like to thank Nikita Aggarwal for conducting some of the interviews, Jessica Brown for her administrative support, and Stuart Hopper and The Modern Law Review's anonymous referee for their comments on an earlier version of this article. Our thanks are finally due to all the lecturers and guests on the 'Law and Computer Science' course, and-most importantly-to Tom Melham for co-convening the course.

\section{The authors declare no conflict of interest.}

\footnotetext{
"Faculty of Law and St Edmund Hall, University of Oxford. Address: St Edmund Hall, Queen's Lane, OX14AR, Oxford, United Kingdom. $\varangle$ vaclav.janecek@law.ox.ac.uk. Corresponding author.

${ }^{\dagger}$ Faculty of Law and Pembroke College, University of Oxford. $\square$ rebecca.williams@law.ox.ac.uk

*Department of Education, University of Oxford. $₫$ ewart.keep@education.ox.ac.uk
} 


\title{
Education for the Provision of Technologically Enhanced Legal Services
}

\author{
Václav Janeček, Rebecca Williams and Ewart Keep
}

\section{INTRODUCTION}

The impacts of digital innovation and artificial intelligence (AI) on skills needs are being studied in many sectors and occupations across the developed world, ${ }^{1}$ and alongside international overviews, there are also attempts to contextualise emerging skills needs within national institutional and policy frameworks. ${ }^{2}$ This article addresses these issues in the context of English legal profession as it is now inevitable that legal services will be transformed by the increasing use of digital technology and AI. Already there are legal startups which provide automated services in place of those traditionally offered in person at a greatly reduced cost and even traditional law firms increasingly rely on digital research and knowledge management tools. This has been highlighted due to the SARSCoV-2 pandemic which has forced most businesses and legal service providers to quickly adopt remote and digital working practices-some of which practices are becoming the new normal. But regardless of the pandemic, legal professionals work with large numbers of textual documents and they need thus to record, transmit and process information on a vast scale. In this regard, the promises of digital technology and AI are evident-they can automate many tasks and processes in relation to which humans are woefully inefficient. Take, for example, a simple ' $\mathrm{Ctrl}+\mathrm{F}$ ' shortcut that saves many lawyers hours of work each day. These technologies can also facilitate entirely new types of legal services. Think of powerful AI-driven tools that some professionals already use in order to extract intelligence from documents reviewed as part of due diligence.

Currently, however, it seems that the adoption of the most advanced lawtech is still relatively low. ${ }^{3}$ Our hypothesis is that this is partly due to various skills and knowledge gaps amongst legal service providers, which gaps prevent lawyers from

\footnotetext{
${ }^{1}$ A Davies, D Fidler and M Gorbis, Future Work Skills 2020 (Institute for the Future for University of Phoenix Research Institute 2011); CB Frey and R Garlick (eds), Technology at Work v4.0 Navigating the Future of Work (Citi GPS: Global Perspectives and Solutions) (Citi/Oxford Martin School 2019); Y Park (ed), DQ Global Standards Report 2019 - Common Framework for Digital Literacy, Skills, and Readiness (DQ Institute 2019); Organisation for Economic Cooperation and Development, The Future of Work - OECD Skills Outlook 2019: Skills and Digitalisation (OECD 2019).

${ }^{2}$ For example, for the UK, see H Bakhshi, JM Downing, MA Osborne and P Schneider, The Future of Skills - Employment in 2030 (Pearson and Nesta 2017); J Djumalieva and C Sleeman, Which digital skills do you really need? Exploring employer demand for digital skills and occupational growth forecasts (Nesta 2018); A Grimes et al., People and Skills: Getting young people 'work ready' - our vision of how education should prepare young people for the modern world (CBI 2019).

${ }^{3}$ In England and Wales, for example, less than a third of lawyers have experience using an AIassisted lawtech in their legal research. See M Sako, J Armour and R Parnham, LawTech Adoption and Training: Findings from a Survey of Solicitors in England and Wales (OUP 2020) 3, 5-6.
} 
unlocking the full potential of AI and digital technology for the provision of their services. While latest scholarship already highlights the need for introducing lawtech in the undergraduate LLB curricula, ${ }^{4}$ it remains unclear what particular knowledge and skills future lawyers will need in order to deploy digital technologies to theirs and their clients' advantage. It is also unclear whether these needs are part of a broader shift towards $21^{\text {st }}$ century skills or are domain specific. We seek to fill this gap.

This paper identifies the skills and knowledge gaps that prevent lawyers from implementing AI and digital technology in the provision of legal services and suggests concrete models for education and training in this area, ie education for the provision of tech-enhanced legal services. Our findings and recommendations are based on a combination of empirical and theoretical research methodologies thanks to which we identify the learning needs and propose how future and established lawyers should be educated so that they can provide technologically enhanced legal services. In particular, we conducted a series of semi-structured interviews with law professionals, designed and delivered an experimental course in 'Law and Computer Science', and analysed the empirical data in view of wider debates in the literature concerning legal education and $21^{\text {st }}$ century skills more generally.

By tech-enhanced legal services we mean services that a client would arguably prefer. Lawyers have a duty to prioritise their client's interests and it is thus plausible to assume that lawyers intend to improve their services primarily because they want better to serve their clients. The tech-enhancement could result in a better price or a superior quality of legal services. It may also lead to tech-enabled services that were not available to the client previously. Of course, much can be said about the potential of AI and digital technology to worsen outcomes for certain groups, but it is evident that there are at least some respects in which such enhancements can work to the benefit of both the law firms and their clients and it is the education necessary to inform the development of such technology with which we are concerned here.

It is also worth noting that $\mathrm{AI}$ and digital technology is likely to impact upon law in two different ways; by affecting legal practice in the ways outlined above, and by presenting challenges to particular areas of law such as employment law, private law liability, competition law and so on. While our research more generally covers both these spheres, this paper is concerned only with the first, or what might be described as the impact of AI and digital technology on 'the process of lawyering'. The skills we identify are not irrelevant even for those who continue in standard legal practice, but for those who wish to augment or automate legal practice in the manner outlined above, they are crucial.

The motivation for this paper is the existing potential for wider deployment of AI and digital technology that would enhance legal services. We focus on the English legal sector because innovative English lawyers are well-positioned to compete for clientele both nationally, thanks to a relatively liberal regulatory landscape, and globally, thanks to the unique combination of this landscape and the strong reputation of the English common law. Besides, a recent report from the European Commission's JRC shows that the UK stands out as a leader in the number of academic programmes in AI domain. ${ }^{5}$ Arguably, there is a great promise for the English legal sector if it can attract the

\footnotetext{
${ }^{4}$ See, eg, C Ireland and R Hockley, 'A call for introducing LegalTech in the classroom' (2020) 36 CLSRev (pages undefined).

${ }^{5}$ M López Cobo et al., Academic Offer and Demand for Advanced Profiles in the EU. Artificial Intelligence, High Performance Computing and Cybersecurity (Publications Office of the European Union 2019).
} 
right talent and if lawyers are adequately prepared to work with computer scientists in order to provide tech-enhanced legal services.

The paper is structured as follows. First, we explain our research methods. Then we provide some background information that will help the reader to contextualise the learning needs presented in this paper. Subsequently, we turn to the gist of our work and discuss the particular learning needs by first addressing some big questions emerging in this field, then by looking at what we propose to be the common core of knowledge and skills that seem to be necessary for the design and delivery of tech-enhanced legal services, then by examining some specific skills and knowledge needs in view of continuous education and training, and finally by discussing a broader trend in the $21^{\text {st }}$ century skills. Next, we outline how these learning needs could be met. The last section summarises our main findings.

\section{RESEARCH METHODS}

This paper results from a large-scale multidisciplinary project titled 'Unlocking the Potential of Artificial Intelligence for English Law' and builds on and complements some of the project's other results. In particular, the paper builds on a literature review concerning education and training for tech-enhanced professional services and legal services in particular. ${ }^{6}$ Further, it is positioned in the context of our review of legal education and qualifications in England and Wales and complements our argument about the future role of universities in this regard. ${ }^{7}$ Finally, it relies on contextual data obtained through the survey of lawtech adoption and training amongst English solicitors (the 'Oxford LawTech Survey'). ${ }^{8}$

The original data supporting the findings and the discussion in this paper come from a series of semi-structured interviews and from our experimental course design and delivery. In particular, we have conducted 16 semi-structured 45 to 90-min long interviews with 19 subjects from a range of professional organisations, namely from large and medium law firms (nine organisations), large and medium legal technology firms (three organisations), the Bar (one organisation), legal information publishers (one organisation) and law libraries (one organisation). The aim of these interviews-all of which were conducted between 2019 and 2020-was better to understand the knowledge and skills gaps that prevent law professionals from enhancing their legal services through $\mathrm{AI}$ and digital technology.

As for the experimental course, in the 2019-20 academic year we designed and launched a masters-level university course titled 'Law and Computer Science'. ${ }^{9}$ The overarching, core theme was to explore how computer scientists and lawyers of the future will need to work together. This two-term course (16 weeks in total) course combined theoretical education with experiential learning in the form of lab sessions and multidisciplinary teamwork. The theoretical education comprised $16 \times 2$-hour lectureseminars, designed to promote in-depth discussion and dialogue between law and computer science. The first half of the course focused on AI and digital technology in

\footnotetext{
${ }^{6}$ E Keep, 'AI and the Law Notes for Lit Rev' (2020), unpublished manuscript.

${ }^{7}$ R Williams, V Janeček and E Keep, 'What is the Role of Law Schools in the $21^{\text {st }}$ Century?' (2020), working paper.

${ }^{8}$ Sako, Armour and Parnham (n 3).

9 The course syllabus and description are available at <http://www.cs.ox.ac.uk/teaching/courses/2019-2020/LawandCS/> (last visited 3 June 2020, https://perma.cc/6DK3-3ES9).
} 
legal practice (the sphere primarily relevant to this paper); the second half of the course on questions of substantive law brought about by such technology (which as noted above, are beyond the scope of this paper). The experiential part of the course was based on a group project (each group containing three students from each discipline) that resulted in a pilot product which was demonstrated in a pitch-like session to experts from the profession. The course brought together twelve students from the Department of Computer Science and the same number of students from the Law Faculty. We surveyed the course participants before the beginning of the course and after it was finished in order to understand better the pros and cons of the various aspects of the course.

\section{CONTEXTUAL INFORMATION}

According to the Oxford LawTech Survey, 90 per cent of English solicitors indicated that they would need some training concerning AI and digital technology in the next three years. ${ }^{10}$ Almost as many respondents stated they would welcome the opportunity better to understand the application of technology to the practice of law by taking a course. ${ }^{11}$ More than 60 per cent of them agreed or strongly agreed that lawyers need to become familiar with multiple non-legal technical specialisms, such as data science, project management, and design thinking. ${ }^{12}$ The most commonly anticipated training needs were: 1. data analytics ( 71 per cent); 2 . legal issues raised by use of AI/technology ( 65 per cent); 3. software packages used by the respondent's employer (61 per cent); 4. ethical issues raised by use of AI/technology ( 48 per cent); 5 . digital literacy ( 45 per cent); and 6 . innovation techniques (44 per cent). ${ }^{13}$ Four in ten solicitors reported that they had already worked in multidisciplinary teams. ${ }^{14}$ Interestingly, no clear preference was given to either teams of multidisciplinary individuals (individual-level multidisciplinarity) or teams of individuals each with different expertise (team-level multidisciplinarity). ${ }^{15}$ This opens up the question as to how best to train these individuals and what kinds of skills and knowledge future lawyers and their co-workers will need.

There are some factual and pragmatic constraints that we should bear in mind when thinking about these needs. AI and digital technology can record, transmit and process information on a vast scale and with absolute precision, but only on the condition that the information is represented in a machine-readable form. A necessary requirement for such technology to be successfully developed and deployed is thus that the relevant information must be produced in this form. So, for example, while an XML document is generally very technology-friendly, a handwritten note on a piece of paper is not. To take full advantage of new technology, we must therefore not only develop the technology itself, but also the world around it, including an in-house legal department, a law firm or a barrister's office to make them tech-friendly. This requires a number of organisational and policy decisions to be made, all of which have some costs and benefits.

\footnotetext{
${ }^{10}$ Sako, Armour and Parnham (n 3$) 9$.

${ }^{11}$ Ibid 11 .

${ }^{12}$ Ibid 15.

${ }^{13}$ Ibid 9.

${ }^{14}$ Ibid 17.

${ }^{15}$ Ibid 16.
} 
This does not mean that if junior lawyers are cheaper than tech development (which our interviews seem to confirm) ${ }^{16}$ legal service providers should resist transformation. If the clients' world is changing and putting an increasing emphasis on tech, then legal professionals should probably try to keep up and avoid deskilling their junior employees, particularly when they are already familiar with tech in various forms. Anecdotally, our interviewees have stressed that '[law firms] have been so good at deskilling [their] people to date ${ }^{17}$ and that 'most junior lawyers are fairly tech savvy and one of the things we hear a lot ... is ... that the tech supporting them in their work is worse than the stuff that they have in their pocket or on their phones. ${ }^{18}$

A strong motivation for more tech-enhanced legal services-and hence for the tech-fuelled transformation of the legal profession-will undoubtedly come from the clients. All our interviews confirmed that legal service providers are heavily driven by the clients' needs and demands. Clients want more for less, which is one reason to turn to technology that could optimise services in this regard. But there is also a growing expectation that technology will be used by lawyers because this is becoming the new standard across other industries as well. As one interviewee noted, '[clients] actually look to test us on our use of technologies or innovation in our service delivery because that gives them an idea of whether we are still very old school in how we are delivering our services or not so much. ${ }^{19}$ The demand is mainly coming from the millennials and from clients who are using technology in their own businesses, as another respondent stated. ${ }^{20}$

Finally, while different legal service providers may need different types of techenhancements and while legal service providers with different business models may have different incentives for development and innovation of their services, the skills and knowledge needs identified in this paper are independent of such considerations. For the purposes of this paper, it is thus irrelevant whether we will see some of the baby boomers starting to move out of the partnership table ${ }^{\prime 21}$ or whether 'the legal sector will be very keen to protect its history, its foundations, ... [because] people worked very hard to attain that badge of being a qualified lawyer in whatever guise that may be..22 We submit that even if the legal sector remains risk averse, which is a feature repeatedly stressed by our interviewees, it may greatly benefit from the learning the set of skills and knowledge identified in the next section.

\section{RESULTS AND DISCUSSION: WHAT ARE THE LEARNING NEEDS?}

Against this background, let us first address some of the 'big' questions discussed in relation to lawtech education. Do lawyers need to code? The programming skillscolloquially referred to as coding-were discussed by most of our interviewees and their responses unanimously suggest that the lawyers do not need to code. As one of them put it, lawyers 'just need to understand how it works, not necessarily how to do it'. ${ }^{23}$ Another

\footnotetext{
${ }^{16}$ One respondent stated that sometimes it makes more commercial sense to use a smarter resourcing level which is, you know, junior, legal resources' ('City law firm 5' interview). Similarly, eg, 'City law firm 2' interview.

17 'City law firm 2' interview.

18 'Global law firm' interview.

19 'Global law firm' interview.

20 'City law firm 5 ' interview.

21 'Medium UK lawtech firm 1' interview.

22 'Medium UK law firm' interview.

23 'City law firm 5 ' interview.
} 
concurred that 'a basic technological awareness or savvy is something we would expect from all our lawyers. ${ }^{24}$

The question whether or not lawyers need to code is, however, problematic because there are many types of coding. To stress this point, imagine a lawyer who reads a letter from their client and who-as part of the process of legal analysis-highlights various sections of the letter in different colours and inscribes various comments in the letter. This lawyer's activity undoubtedly amounts to coding, although we would not describe it as programming. It is coding that encodes the client's letter as a solvable legal issue. From a computer science viewpoint, then, coding need not to refer only to scriptwriting in a programming language but also to software development and programming broadly construed. If that is the case, then we can say that software development involves coding at various levels, including the task of analysing the problem at the correct level of abstraction where the 'coded' issue represents a class of intellectual puzzles that can be solved by mechanical means, that is a computable problem. To some extent, this analytical coding of real-life issues (which is a pre-condition for computer programming and software development) is very similar to lawyers' coding. So, let us ask again: Do lawyers need to code? Of course. Do they need to code legal issues for computers? Yes, if they want to make those issues tech-friendly. Does that mean they need a high level of expertise in a particular programming language? Not necessarily.

Another big question is this: Should lawyers replace some of their present knowledge and skills-set with non-legal expertise, or do they need just an additional layer of knowledge and skills? It is clear that the answer is the latter. ${ }^{25}$ As our other work (drawing on that of Spencer, Smith and Susskind) ${ }^{26}$ makes clear, ${ }^{27}$ it is vital that lawyers retain a detailed understanding of the law as a precursor to any engagement with the associated technology. Nonetheless, the development and provision of tech-enhanced services demands skills and knowledge that traditional lawyers do not possess, and this demand can be met either by multidisciplinary teams or by multidisciplinary individuals. Depending on the particular circumstance of the lawyer and his or her organisation, the choice between these two might differ. In general, it could be more difficult for individuals to become fully multidisciplinary as opposed to simply able to communicate effectively with another discipline, but from an economic viewpoint team-level multidisciplinarity may not be preferred by organisations that cannot afford to pay multiple employees. Also, we should keep in mind that future generations of lawyers are likely to be more digitally literate that those who dominate the market today. In any case, it seems that lawyers expect their future trainees and workforce to be a little bit more multidisciplinary than they are today. ${ }^{28}$

If future lawyers should master an additional layer of skills and knowledge, however, this seems to imply that some of their traditional knowledge and skills will become less relevant because there is a limit to what one can realistically do during his or her worktime. And so, depending on the nature of the tech-enhanced services, lawyers may for instance no longer need to master the skill of traditional contract or testament drafting. Surely, lawyers will need to review contracts and testaments for their clients, but the processes leading to this outcome are likely to change in the future. This begs another

\footnotetext{
24 'Global law firm” interview.

${ }^{25}$ eg, 'Large UK law firm 1' interview.

${ }^{26}$ A Smith and N Spencer, 'Do Lawyers Need to Learn to Code? A Practitioner Perspective on the "Polytechnic" Future of Legal Education' in C Denvir (ed), Modernising Legal Education (CUP 2020); R Susskind, Tomorrow's Lawyers: An Introduction to Your Future (OUP 2013) 118-20,

${ }^{27}$ Williams, Janeček and Keep (n 7).

${ }^{28}$ eg, 'City law firm 5' interview.
} 
big question, namely whether certain types of person are more fit for lawtech education and training than other types? Are, for instance, outcome-oriented people better fit for lawtech education than process-oriented people? Are the young a better fit for lawtech education than the old? We submit that they all are fit for lawtech education and training and that this person-type dilemma is in fact a question about the organisational set-up and where different types of person can bring most value to the client and to the business. From a credibility standpoint, for instance, lawyers 'need to be the ones ... the boards rely on', as one senior solicitor noted. ${ }^{29}$ Similarly, if your business model would be to provide technology to a law firm, then being a lawyer gives you credibility because you better understand the daily problems of your clients-other lawyers. ${ }^{30}$ The question is whether there is a meaningful set of skills and knowledge can be defined in order to establish some benchmark credibility of a multidisciplinary individual, or a minimum viable combination of skills and knowledge that an multidisciplinary legal technology team should embody in this regard. In the next section, we define such a core set of skills and knowledge.

\subsection{The common core of lawtech skills and knowledge: The Legal Technologist}

One of the weaknesses detectable in the global literature on digital technologies and emerging skills needs is that the literature discusses generic frameworks that are incapable of grounding new learning and skill requirements within the context of specific bodies of occupational knowledge, practice and regulation. ${ }^{31}$ Without research that addresses sectoral and occupational needs and circumstances it is hard to deliver sufficiently detailed and contextualised learning requirements for education and training providers to be able to respond effectively. These kinds of sectorally-focused research studies are still relatively rare in the UK. This study aims to add further detail to an emerging picture. $^{32}$

On the basis of our research interviews we identify five main areas of learning needs amongst all sorts of current and future law professionals who would want to provide tech-enhanced legal services: 1) Mindset understanding; 2) Data-oriented thinking; 3) Agile systems and design thinking; 4) Commercial awareness; 5) Digital ethics and the law of AI and digital technology. The five areas-which we will explain in more detail below-are relatively stable in the sense that they appear to represent the minimum required set of skills and knowledge in relation to a wide range of tech and tech-enhanced legal services. Our view is that these five areas could be seen as the common core of lawtech skills and knowledge that are significant for any tech-enhanced legal services. This common core also currently represents the learning needs that exist in the legal market and prevent lawyers from using AI and digital technology in their practice. Accordingly, we think that these learning needs should be recognised by the sector and responded to by adequate educational and training provision.

\footnotetext{
29 'City law firm 4' interview.

30 'Medium UK lawtech firm 2' interview.

${ }^{31}$ E Keep 'Reimagining Jobs, Skills and Education for the Digital Age - Initial thoughts and issues' Digital Futures of Work RS3 Paper No.1 (Institute for Adult Learning 2020).

${ }^{32}$ Within legal services, examples would include A Cunningham, AD James, P Taylor and B Tether, 'Disruptive Technologies and Legal Service Provision in the UK: A Preliminary Study' (Manchester University, School of Law and Alliance Manchester Business School 2018); The Law Society, Lawtech Adoption Research (The Law Society 2019); Smith and Spencer (n 26).
} 
We also believe these areas to have synergies, in the sense that a grasp of all these skills might be greater than the sum of those skills individually. To this end, the learning needs around the common core of lawtech skills and knowledge could be satisfied by a one-off educational investment which might also draw out those synergies. Some form of certified qualification would thus enable law professionals and lawtech entrepreneurs more easily to create teams that would bring together these unique capabilities. However, it is too early to tell whether a degree-level qualification is needed for this kind of role or, most importantly, how big the market demand for such a role would be when the first graduates obtain such a degree. At this point in time, it seems likely that these skills will be acquired gradually by individuals in the form of continuous professional development, rather than as a single formal qualification, though again this may change in the future. At this stage of our research, we merely identify those skills and knowledge needs without taking a view on how best to certify the required set of individual- or team-level capabilities.

For the purposes of this paper, we will use a term 'Legal Technologist' when referring to a person who masters all five areas of the common core of lawtech skills and knowledge. The phrase 'Legal Technologist' came up several times during our interviews as a title for an emerging new role.

\subsubsection{MINDSET UNDERSTANDING}

The first area can be broadly described as 'mindset understanding' because it refers to the need of lawyers to understand a computer science mindset, to learn its strengths and limitations, to learn about professional and personal motivations of computer scientists, their language and culture, and to appreciate the similarities and differences between lawyers and computer scientists. A neat way to test how good a Legal Technologist is would be to ask them to tell a joke at which only 'the other' discipline will laugh.

What all of our interviewees reported and our course experience confirms is that Legal Technologists will need to communicate with both lawyers and computer scientists. In multidisciplinary teams, for instance, this would mean that a Legal Technologist will act as a translator between the two disciplines, which also requires a solid grasp of the respective jargons. This is why some lawyers believe that 'there's a huge scope for training people to be able to look through all the jargon' ${ }^{33}$ There are notions which are domain-specific such as 'consideration' for lawyers or 'arrays' for computer scientists. Some notions are common to both fields but mean something different in each of them. For instance, when lawyers say: 'You can't do this', they typically mean to say that the activity is legally forbidden. By contrast, computer scientists would use the same utterance to point out that something is physically impossible, unless someone shows them otherwise. The logic behind the language is different too. To a computer scientist the question 'Do you want tea or coffee?' ought technically to be met with a simple 'Yes' or 'No'.

Apart from the linguistic differences, which are perhaps the most obvious, there are different expectations as to what is the gold standard of one's work. In computer science, for instance, the solution either works or it does not. In other words, there is almost always a correct answer to the problem. In law, by contrast, the offered solution is mostly regarded successful if it considers all the possible arguments and legal risks. ${ }^{34}$ Lawyers tend to be comprehensive, whereas computer scientists tend to be effective. So

\footnotetext{
33 'City law firm 2' interview.

${ }^{34}$ See, eg, 'Medium UK lawtech firm 2' interview and 'Medium UK law firm' interview.
} 
while computer science is more outcome-focused, a lawyer's mindset is more processoriented. This distinction, which was strongly present also throughout our 'Law and Computer Science' course, could perhaps be explained by reference to procedural justice which is vital for law but irrelevant for computer science. A legal outcome is commendable and regarded as just not least because it is substantively just, but also largely because it has been achieved through the right legal procedures. These procedures may not be the most efficient, but lawyers regard it as part of their role to protect the process because it is fair to do so in relation to others. In computer science, by contrast, the notion of fairness is troublesome. There is no strict requirement to follow certain procedures as long as those procedures achieve the desired outcome and function as required and specified.

There are also different career motivations and work patterns. While both disciplines are driven by excellence and quality, lawyers' thinking is typically bound to a specific jurisdiction, whereas computer science is a domain of nearly a global standard. To this end, it is not surprising that the churn rate of developers is astronomical because developers love coming in on a project that they were recruited for, and then finishing that project and then finding another project, and they don't have a problem we're getting another job because developers are in such high demand at the moment. ${ }^{35}$ Lawyers do not think this way about their jobs. The requirements of loyalty to the client and the duties owed to the client by a lawyer are entirely unknown in the world of computer science.

Culturally, there are also different expectations. This concerns the dress code, working hours, work-place set-up, snacks, employee benefits, etc. One of our interviewees admitted to having been taken by surprise by how different a typical workday of a computer scientist and a lawyer might be. One of the reasons was that a computer scientist is actually coding the rest of the time. So she actually needs an actual break in a way that lawyers generally have less of because of what she's doing she's not her most concentrated in the afternoon if she doesn't have an actual break'. ${ }^{36}$ This could be further related to an important observation by the participants in the 'Law and Computer Science' course. They noted that there is a big distinction between the reactive legal mindset and the pro-active mindset of computer scientists. In law and legal practice, lawyers in practice do not as often pro-actively create and design new things. Our interviews suggest that the process of lawyering is often more repetitive than the process of computer programming. A legal mindset discourages people from taking risks, whereas computer scientists are more attracted to ideals of intellectual freedom and the beauty of a well-designed system. This, of course, does not apply equally to all areas of legal practice, but even creative activities such as legislative drafting are affected by the required traditional procedures and by the tendency to be exhaustive and complex. By contrast, highly complex computer systems are typically also highly insecure and thus not recommended. Arguably, the room for new creations and active development is therefore typically much bigger in computer science than in law.

Both our interviews and the course survey clearly confirm that the need to learn the other discipline's mindset, including its strengths and limitations, helps lawyers and computer scientists to work together. For example, one law student said: 'I was also grateful to be able to speak to, and ask computer scientists about the technicalities of certain codes, amongst other technical discussions.' While another law student told us that: 'The worst aspect of the interdisciplinary coursework with my peers from my cohort

\footnotetext{
35 'Medium UK lawtech firm 2' interview.

36 'City law firm 3’ interview.
} 
lies in the differences in methodology, language and culture of law and computer science and this accounted for why it was, at some points, difficult for us to agree on some salient issues. Happily this is part of the training and I developed new skills in dealing with interdisciplinary issues.'

Moreover, this interdisciplinarity also allows each discipline to reflect upon itself. As our interviewee summarised, 'I think people would enjoy having to rethink areas that they feel confident in'. ${ }^{37}$ According to one of our computer science students, an interdisciplinary education and collaboration 'allows one to really take a step back on the code, the maths and ask ourselves higher-level questions ... Interacting with lawyers permitted [us, that is computer scientists,] to confront and compare our point of view and reflect on our own knowledge and mindset, but also understand how our discipline is perceived by another. I really believe these kind of reflections are crucial for computer scientists, and traditional computer science courses could not have provided them'. Similarly, one of our law students commented that 'this course allowed for a conversation about the law with students from another discipline and I honestly feel this increased my personal understanding of the law by leaps and bounds.'

\subsubsection{DATA-ORIENTED THINKING}

Another important area of knowledge and skills can be described as data-oriented thinking. Lawyers and their clients produce huge amounts of documents and information-heavy resources, but they do not always think about these resources as data and about themselves as data producers. Every (e)mail correspondence, every contract draft, every memorandum or analysis, all these contribute to the sky-rocketing pile of data of various formats and quality. As our research suggests, in law firms these data are mostly unstructured and often binned in a folder labelled as 'other' data (if they are labelled at all). The most structured data are often related to specific digital technology product that the law firm uses, but lawyers 'shouldn't think about our data as being related to a particular product ${ }^{38}$ if they want their valuable data resourced keep untapped for the future.

An understanding of data science and databases, as well as the ability to think about legal services as a data-rich resource, is what Legal Technologists need. As pointed out by our respondents, law firms 'would desperately like people to think about the data they're producing and the documents that they produce' ${ }^{39}$ Legal Technologists should thus be able to understand and design knowledge management systems where as much data is put to use as possible. From a legal research perspective, this is also important because lawyers want to make sure their research is complete. '[I]t's great if you can make sure you manage to search everything. ${ }^{40}$

At the same time, Legal Technologists should also be able to unlock the potential of data by training in data formats, data structures and by greater appreciation of consistency. While the legal craft is often linked with the ability to present an argument, Legal Technologists should be able to take a step back from the presentation and identify the underlying data structures or impose a new structure on top of the presented material. For machines 'it's just so easy for them to get lost', ${ }^{41}$ unless the same entities are

\footnotetext{
${ }^{37}$ Ibid.

${ }^{38}$ Ibid.

${ }^{39}$ Ibid.

40 'Law library' interview.

41 'Legal publisher' interview.
} 
consistently identified throughout the dataset. And so, while a poetic presentation and varying ambiguity might be more human-friendly and successful with the human end user, a bullet-proof uniformity with defined hierarchies is what machines prefer.

Tech-enhanced legal services thus demand lawyers to have 'a data and capability strategy, and that should take into account not just practice data but also this business data ... But designing that strategy is really hard', as our respondent noted ${ }^{42}$ It is, nevertheless, one of the core conditions if lawyers want to provide tech-enhanced legal services and our research clearly confirms that data-oriented thinking is a must for Legal Technologists.

\subsubsection{AGILE SYSTEMS AND DESIGN THINKING}

The third significant knowledge and skills need for Legal Technologists emerges around mental agility in combination with systems and design thinking. It includes the ability to abstract a correct intellectual puzzle so that it is solvable by an existing or yet-to-be invented digital technology. It also includes the ability to think about problems as abstract classes of problem. The lesson from computer science here is clear-unless we know how to solve the problem, we have not yet adequately defined the problem as a tech-friendly problem. This requires a lot of mental agility, the ability to explore the problem from a systemic viewpoint, and eventually to (re)design the system or the problem-all of which are skills not very typical of lawyers.

The good news is that these are transferable skills and our research and teaching experience shows that they can be taught. Of course, it may be true that 'lawyers don't like to say I don't know', ${ }^{43}$ but it is important to learn how to function flexibly in an unfamiliar situation, to try to build something, possibly to get it wrong the first time, learn from it, and try again. For qualified lawyers, this may be difficult because '[i]t's a long time since they've had a beginner's mindset. How do you cope with actually getting something wrong, which you generally don't do?'44

The answer is partly in adopting the agile mindset. '[H]istorically [this is different from] how lawyers were viewed which is very risk averse and change averse. And it is important to change that mind set for lawyers to be good practitioners in the future because change is happening and will happen and they need to be agile enough to be able to deal with it. ${ }^{45}$ Agile decision making and agile methodologies are familiar to tech people. ' $[\mathrm{A}]$ tech person is by definition ... very fast moving ... very flexible ... ultrahighly competitive. Law firms aren't like that', according to one of our respondents. ${ }^{46}$

An important part of this skillset is creativity, which again is something that our interviewees thought lawyers generally lack. By contrast, they reported that the most advanced computer programme builders often have some background in visual arts and music. For example, one was 'traditionally a composer, and part of that was he understood structures and rules, but could sort of freestyle within that and could really express creativity within that' ${ }^{47}$ This could perhaps be partly attributed to the fact that artists are limited by the nature of their tools and materials (similarly to how Legal Technologists will be limited by the nature of data), on the one hand, and that artists also know how to build and combine things together in a way that can be presented to the

\footnotetext{
42 'City law firm 3' interview.

43 'City law firm 1' interview.

44 'City law firm 3' interview.

${ }^{45}$ 'Global law firm' interview.

46 'Medium UK lawtech firm 1' interview.

47 'Global lawtech firm' interview.
} 
consumer, on the other hand. What Legal Technologists could learn from this is the need to respect the input limitations (data) and to design the best possible output (techenhanced service) that would bring the client also a good user experience. Again, our research confirms the importance of at least some mastery of the user experience (UX) and user interface (UI) fields. ${ }^{48}$

All this requires Legal Technologists to think about tech-enhanced legal services as systems, rather than off-the shelf products. They need to be able to update and upgrade those systems to maintain continuity and, as noted above, fairness in the legal sense of legal certainty and procedural justice. Legal Technologists thus need to find 'tangible ways for people to understand problems, and the ways that they might-the ways that we might try and tackle it in the future. ${ }^{49}$ Legal Technologists, it seems, should be trained to design functioning tech-enhanced systems or tech-enhanced products and services within systems that they understand.

It should be noted that the fact that we expect those working in the area of legal tech to have such skills is not exclusive of the necessity of such skills for 'ordinary' lawyers who continue to work within the core of the legal practice. Unless such lawyers have an instinct that there might be a tech-friendly problem on their desk, or that they have access to a potential source of useful data, they will not know when exactly to contact those in the legal tech field who might more readily be able to take these instincts further. Similarly, the responsibility for auditing and checking matters such as fairness and legal certainty of the system adopted will remain with the firm as a whole, not simply with the Legal Technologists. The line between Legal Technologists and 'ordinary' lawyers need not necessarily be sharp. Nonetheless, there will be some who are more specialist in these matters than others and it is these people we identify as potential Legal Technologists.

\subsubsection{COMMERCIAL AWARENESS}

The fourth area can be labelled commercial awareness. This, again, emerged as a core requirement for the Legal Technologist role during our interviews and course experimentation. '[P]eople don't say to you, "I want the tech solution," or, "I want the outsource solution," what they say is, "How are you going to demonstrate you've done it cheaper?" And so, it's always a bit of both, essentially. ${ }^{50}$ Accordingly, one part of the skills package needs to be this commercial awareness, ie the ability to appreciate the client's interests and also the real-world limitations for any potential solution. There is the client's business and then there is the lawyer's business and each of them have their constraints.

At least some elementary experience with project planning and management are rightly considered a necessary background that Legal Technologists should have as part of their commercial awareness. To this end, it is important to bear in mind that a legal business is run differently from a tech business and insights into both of them are essential. '[E]veryone knows that tech is out there, that $\mathrm{AI}$ is coming blah blah blah, but on a daily basis, it's quite hard sometimes to make money out of it. ${ }^{51}$

There are some domain-specific pragmatic limitations that Legal Technologists should also be aware of. Some vital resources such as people and their skills, time, cashflow, high-quality data, computing power, storage capacities, or software licences are

\footnotetext{
${ }^{48}$ eg, 'Medium UK law firm' interview and the 'Law and Computer Science' course.

49 'City law firm 3' interview.

50 'City law firm 2' interview.

${ }^{51}$ Ibid.
} 
limited. These considerations should be taken on board in tandem with law-specific requirements such as confidentiality of data, security of systems, or integrity and independence of the legal service. One needs to know, or at least be aware of, these benchmark limitations and factor them into project planning and management.

Finally, commercial awareness, as understood here, includes the ability to focus on the outcome in the sense that a vision of an optimal yet pragmatically unfeasible solution should not deter Legal Technologists from releasing a good solution that is feasible. Lawyers are not typically trained this way because, by the very nature of the profession, lawyers do not advise their clients to take risks. This ability requires Legal Technologists to think, at least in part, unlike lawyers and to weigh benefits and potential damages to the client, the tech-enhanced legal business, and potentially to others. Sometimes, this commercial awareness will allow lawyers to offer their clients a more considered range of options; sometimes, it will allow lawyers to better choose the optimal route for themselves. The ability to weigh the risks and benefits in situations unregulated by the law can perhaps best be gained by training in applied economics, management, and applied ethics. Again, it is not that lawyers in standard practice will be able to avoid the striking of such balances. On the contrary, it is those responsible for the policy choice whether or not to adopt or deploy a particular piece of technology who will have to make the final call on such issues. Nonetheless, the Legal Technologist can play an important role in identifying and setting out the choices to be made.

\subsubsection{DigiTAL ETHICS AND THE LAW OF AI AND DIGITAL TECHNOLOGY}

The fifth and final area that our research shows to be part of the common core of skills and knowledge that any Legal Technologist should possess covers digital ethics and the law of AI and digital technology. ${ }^{52}$ As one interviewee noted, 'it's so much fun training a model and seeing it make predictions that are accurate, but the problem is the better at it you get the more dangerous it can be. ${ }^{53}$ Tech-enhanced legal services are on the rise and so is still the entire field of new digital technologies, including machine learning, deep learning, or quantum computing. As was mentioned above, lawyers are reactive. In fact, law is ultimately designed to provide stability to aspects of our social life by pronouncing some interests to be legally protected. Generally, however, this often means that our social life is ahead of the legal system and that legal regulation merely catches up with societal changes. This is even more true in relation to new digital technologies and technological transformation more broadly.

Legal Technologists can be expected to play an important role within a firm or other legal service provider on three levels in this respect. First, the same issues such as data protection or liability for software will keep popping up in relation to tech-enhanced legal services and so Legal Technologists should have a good knowledge and understanding of this law.

Second, they should know how to set the right path in digital domains not so well regulated by the law and indeed they would be in a good position to contribute to the work of regulators as the latter grapple with new issues. Thanks to the use of new digital technologies, we can see more clearly some of the problems in the existing laws and legal services. For instance, where previous legal decisions are now used as AI training datasets, we can detect how implicitly biased some of those decision-making practices were. This

\footnotetext{
${ }^{52}$ See, eg, A Murray, Information Technology Law (4th edn, OUP 2019); M Hildebrandt, Law for Computer Scientists and Other Folk (OUP 2020).

53 'Legal publisher' interview.
} 
technological ability gives us the opportunity to rethink some of the fundamental assumptions of our law and legal system and to offer new, presumably better answers to societal problems. To this end, training in digital ethics is necessary. Coincidentally, this area proves to be of great interest to university students and professionals from both law and computer science, as our research data shows. Importantly, any training in digital ethics and any education in law of AI and digital technology should be coupled with a good understanding of the relevant digital technology's architecture, its basic capabilities and limitations.

And finally, Legal Technologists could become a useful resource within the organisation itself. It is worth noting that knowledge of the law relating to AI and digital technology is, again, not something which applies uniquely to Legal Technologists to the exclusion of 'ordinary' lawyers. While Legal Technologists will require this understanding specifically in relation to technology for supporting and enhancing legal services, increasingly lawyers across the sector will require an understanding of how traditional areas of law such as competition, employment or public law must also respond to the presence of AI and digital technology as well as humans. Nonetheless, while these individual areas of law will not be their speciality, Legal Technologists might be able, within and across an organisation, to provide an additional source of guidance and understanding on such issues and particularly the technology involved.

\subsection{Beyond the Legal Technologist: Specific and continuous learning needs}

While the previous set of Legal Technologist's knowledge and skills are to give one a baseline credibility and qualification to design and deploy tech-enhanced legal services, there are also specific learning needs that will continuously change and that will continuously be required. Most commonly, our interviewees highlighted this demand in relation to various technology-specific, service-specific, role-specific and time-sensitive skills and knowledge. Our contention is that these learning needs should be met, but there is no need to view them as a universal qualification. To this end, they will probably best be met by self-contained units of training and education, for example as part of one's continuous professional development (CPD) or executive education (ExecEd). One-off sessions concerning digital ethics, introduction to artificial intelligence (AI), and review lectures about existing technologies, or product-specific training were identified by our respondents as examples of such learning needs.

One of the limitations as well as reasons for these specific needs is that one cannot train for a role that does not yet exist. All our respondents seem to concur with the statement that 'until AI and digitalisation in the sector is broadly adopted, because it's not at the moment, it's hard to know if there is a training gap' ${ }^{54}$ What is more, $\mathrm{AI}$ is perceived to be light years ahead of where the market is at', ${ }^{55}$ and it is felt that we are in a situation where it is accepted that some 'game changing innovation that everyone assumes is going to happen but nobody knows what it is yet, ${ }^{56}$ This, for obvious reasons, requires the educational and training sector to be able flexibly to react to such specific learning needs.

By contrast, the benchmark set of five learning goals for a Legal Technologist are transferable across the legal sector, roles, products and services as well as different generations of legal service providers. Those skills are unlikely to be dated soon-a worry that our interviewees often expressed in relation to any accredited qualification. They

\footnotetext{
54 'Medium UK law firm' interview.

55 'Medium UK lawtech firm 1' interview.

56 ‘Global law firm’ interview.
} 
feared that since the field is moving fast, any detailed specification of a role or an educational model will become irrelevant soon. ${ }^{57}$ At the same time, they stressed a lack of theoretical background and some more solid pieces of critical knowledge that would be provided around legal technology ${ }^{58}$ The Legal Technologist's learning needs-as defined in this paper-thus comprise skills and knowledge that should be recognised and demanded by the market if we want more tech-enhanced legal services to be available. This does not imply that a new career type must emerge on the market, but it suggests that the market should require this combination of skills and knowledge to be brought together in one way or another.

\subsection{Comparison with a broader trend regarding $21^{\text {st }}$ century skills}

How do these findings compare with the broader literature on the skill requirements being driven by digital technologies and what are sometimes termed ' $21{ }^{\text {st }}$ Century Skills'? In general, the skills needs identified through our research appear to fit neatly within the broader discourse and its models of future learning requirements. As in the wider research and policy literatures, the picture is one of need for a fusion between a broad foundation of knowledge and awareness of technology and its potential applications, and a set of soft skills that facilitate the introduction and usage of new technologies within different workplaces and teams. ${ }^{59}$ For example, Garlick suggests that the skills needed to thrive in a more digitalised world and labour market will be: critical thinking and problem solving, creativity, communications, and collaboration. ${ }^{60}$

The findings also tend to mirror the overall shape of findings from similar investigations of future skills needs in law in the USA. The picture that emerges is one of a need for an appreciation of technology's potential to drive change coupled with a set of broad, generic skills, aptitudes and dispositions, such as personal effectiveness, which are then broken down into competencies such as entrepreneurial mindset, adaptability and emotional intelligence, ${ }^{61}$ or what Smathers has termed the T-shaped lawyer. ${ }^{62}$ This

\footnotetext{
${ }^{57}$ eg, 'City law firm 1' interview, 'City law firm 3' interview, 'Large UK law firm 1' interview.

${ }^{58}$ eg, 'Large UK law firm 1' interview, 'City law firm 3' interview.

${ }^{59} \mathrm{C}$ Fadel, '21st Century Skills: How can you prepare students for the new Global Economy?' (OECD/CERI 2008); The Partnership for 21st Century Skills, '21st Century Skills: Education \& Competitiveness - A Resource and Policy Guide' (Partnership for 21st Century Skills 2008); Davies, Fidler and Gorbis (n 1); B Trilling and C Fadel, 'Tactics for Success' (2012) 158(5550) RSA Journal 10; M Bialik and C Fadel, Skills for the 21st Century - What should students learn? (Center for Curriculum Redesign 2015); European Political Strategy Centre, 'The Future of Work - Skills and Resilience for a World of Change' (2016) (13) EPSC Strategy Notes; E van Laars, JAGM van Dijk, AJAM van Deursen and J de Haan, 'The relationship between 21st-century skills and digital skills: A systemic literature review' (2017) 72 Computers in Human Behaviour 577; TA Singlehurst, N Pajaver, E Curmi, R Garlick and R Nabarro, Education: Back to Basics - Is Education Fit for the Future? (Citi 2017); T Ravenscroft and L Baker, Towards a Universal Framework for Essential Skills - A Review of the Skills Builder Framework (Chartered Institute of Personnel and Development 2019); Organisation for Economic Cooperation and Development, OECD Future of Education and Skills 2030 Conceptual Learning Framework (OECD 2018); Frey and Garlick (n 1); World Economic Forum, Schools of the Future - Defining New Models of Education for the Fourth Industrial Revolution (WEF 2020).

${ }^{60}$ R Garlick, 'Conclusion' in Frey and Garlick (n 1) 151-57.

${ }^{61} \mathrm{~N}$ Runyon and A Carrel, Adapting for 21st Century Success: The Delta Lawyer Competency Model (Thomson Reuters 2019).

${ }^{62}$ RA Smathers, 'The 21st-Century T-Shaped Lawyer' (2014) Law Practice Magazine 34.
} 
concept reflects wider educational debates about the need to create T-shaped courses ${ }^{63}$ that instead of simply delivering the long, vertical stem of specialised technical skills and knowledge (in this case of law) were also capped by a transversal element of generic business and digital skills and understanding that can support the mobilisation of knowledge in support of organisational/business objectives; and adaptability, future learning and upskilling. Demands for T-shaped skill profiles and legal education courses are thus by no means unique to legal education and simply mirror similar developments in many other fields of vocational and professional education. ${ }^{64}$

Finally, the study's findings for legal services in England are not dissimilar to those for a very different segment of the economy-construction.$^{65}$ Future skills need identification work undertaken by the Construction Industry Training Board (CITB) indicated that digitalisation of many aspects of their sector was driving demand for two skill sets: one to do with soft skills (a flexible mind set, curiosity, problem solving, creativity, emotional intelligence and communication), and the other concerned with technological understanding and awareness (understanding tools and data; knowledge of how specific technologies work; awareness of the technology available or being developed; how data can support technology's application; and collecting, storing, sharing and using data).

Nevertheless, there is one aspect in which digitalisation in the legal domain-as opposed to other high-value professional services such as banking, insurance, and accounting-requires distinct skills and knowledge. Whilst economic information and theories that underpin banking, insurance and accounting can often be modelled and specified in a computable way, legal information and jurisprudential theories are much more problematic in this regard. Foundational legal concepts such as reasonableness or fairness are wide open to possible interpretations and can hardly be automated. ${ }^{66}$ Not everything that matters for the provision of legal services can be digitised and not everything that can be digitised matters for the provision of legal services. In this regard, we think it will be particularly important for future lawyers to have a good understanding of the computer science mindset and a solid grasp of digital ethics and the law of AI and digital technologies, because this will help them translate the high-level ethical or legal requirements into more tech-friendly specifications and also to consider which aspects of legal services cannot or should not be automated. ${ }^{67}$

\section{RECOMMENDATIONS: HOW TO MEET THOSE NEEDS?}

It is one thing to identify the learning needs and another thing entirely to find ways to satisfy those needs. There is a large body of literature dealing with education and

\footnotetext{
${ }^{63} \mathrm{~S}$ Glasbeek, The importance of transversal skills and competences for young people in a modern Europe, (AEGEE Europe 2018).

${ }^{64} \mathrm{Ibid}$. See also World Economic Forum above n 59.

${ }^{65}$ Construction Industry Training Board Unlocking Construction's Digital Future: A Skills Plan for the Industry (CITB 2018).

${ }^{66}$ See, eg, S Wachter, B Mittelstadt and C Russell, 'Why Fairness Cannot Be Automated: Bridging the Gap Between EU Non-Discrimination Law and AI' (2020), working paper available at $<$ http://dx.doi.org/10.2139/ssrn.3547922>.

${ }^{67}$ In European data protection law, we can already see scholars attempting to provide of such a translation-V Janeček and G Malgieri 'Commerce in Data and the Dynamically Limited Alienability Rule’ (2020) 21 German Law Journal 924, 938.
} 
educational methods generally ${ }^{68}$ as well as in law, ${ }^{69}$ all of which can be utilised for future curricula that would aim to meet the relevant learning needs. Moreover, in the context of lawtech, some professional organisations are now actively exploring ways to develop lawtech training (sometimes in collaboration with universities). ${ }^{70}$ Universities collaborate and share experiences too. ${ }^{71}$ It is not without interest that Legal Technologist has already been accredited as a qualification in Scotland, ${ }^{72}$ and that the Legal Services Board, The Law Society, or LawtechUK now actively explore this area. ${ }^{73}$ In this section, we want to provide a structured overview of some of the issues that came up as significant during our research in relation to the provision of lawtech education and training.

At least five significant perspectives could be discussed in this regard. The first is an organisational perspective. What should the organisation that aspires to provide techenhanced legal services do to satisfy the learning needs of Legal Technologists? Some interviewees reported that it is helpful to have a digital strategy, since that promises to attract the right talent. ${ }^{74}$ But a practical trouble then seems to be that lawtech training and learning needs are not the priority. More often, it seems that senior lawyers who work in law relating to digital technologies, knowledge managers, innovation departments, or business department are those who take the lead on lawtech education, whereas learning and development departments in law firms are standing aside. As one interviewee accurately spotted, 'I don't think it's going to work in the long run if L\&D teams are very much waiting for their head of innovation to say we need this training; it needs to be aligned'.$^{75}$ A quick patch for what we see as an unsystematic approach to lawtech education in law firms is that the firms will provide some lawtech training to their own clients. As a number of our interviewees admitted, this is a very effective way for them to learn new things too. Some of them even reported an increasing popularity of placements that allow lawyers to spend several months in another department or with the client. These options are certainly worthwhile, but from an educational viewpoint, we suspect that the learning curve could be improved where these initiatives are coupled with educational expertise.

\footnotetext{
${ }^{68}$ See, eg Review of Research in Education, Educational Research Review, Review of Educational Research, and Critical Studies in Education.

${ }^{69}$ See, eg, Journal of Legal Education, Journal of Legal Studies Education, and European Journal of Legal Education.

${ }^{70}$ See, eg, Society for Computers and Law (SCL), British and Irish Association of Law Librarians (BAILL), Corporate Legal Operations Consortium (CLOC), Research Meets Practice (ReMeP), Legal Cheek, Legal IT Innovators Group (litig), Legal Technology Core Competencies Certification Coalition (LTC4), European Legal Tech Association (ELTA), International Legal Technology Association (ILTA).

${ }^{71}$ eg, Law and Technology Education Network (LTEN), British and Irish Law Education Technology Association (BILETA), Australian Legal Technology Education Network (ALTEN), Bucerius Legal Tech Essentials.

72 See Law Society of Scotland, 'Accredited Legal Technologist' at $<$ https://www.lawscot.org.uk/members/career-growth/specialisms/areas-ofspecialism/accredited-legal-technologist/> [https://perma.cc/TBY6-EYRX].

73 Legal Services Board, 'Technology and Regulation' at <https://www.legalservicesboard.org.uk/our-work/current-work/technology-and-regulation> [https://perma.cc/6BY5-GMLK]; The Law Society, 'Lawtech' <https://www.lawsociety.org.uk/campaigns/lawtech> [https://perma.cc/P38B-J2ZR]; LawtechUK, 'Online Hub and Training Centre' at <https://technation.io/lawtechuk-vision/\#online-hub-andtraining-centre> [https://perma.cc/KPL7-ZW9H].

${ }^{74}$ 'Medium UK lawtech firm 1' interview.

${ }^{75}$ 'City law firm 3' interview.
} 
Then there is the individual's perspective. Repeatedly, our interviewees stressed that they are providing legal services and so although all their legal tech recruits need not necessarily have formal legal qualification, legal service providers will 'ultimately ... want lawyers who are excellent at executing legal tasks' ${ }^{76}$ Not everyone thus needs to become a Legal Technologist (or a certified Legal Technologist) and not all Legal Technologists need to have the same experience in law. Examples of successful automation and transformation projects in law firms suggest that 'value can't be realised unless you have thought through your use case really well and you know the problem you are trying to solve. So empowering people to engage with lawyers as subject matter experts or others who have that knowledge in their head, get it on paper, make sure it is scoped out well and there is purpose in it. ${ }^{77}$ In this regard, seasoned legal experts are likely to have very different learning needs, because their contribution to their law firm as Legal Technologists (or when working with Legal Technologists) would differ from the contribution which is to be expected from a junior lawyer. ${ }^{78}$ For example, experienced lawyers will typically have much broader, systemic understanding of the problems that are associated with the provision of legal services than junior lawyers. The decisionmaking processes in law firms seem to reflect this. As revealed to us during the interviews, one of the reasons why senior lawyers are more trusted with strategic decisions is that they are likely to be good at systems thinking and systems analysis, whereas junior lawyers seem better positioned to (re)design legal services with a clearly outcome-focused mindset. It should be noted, though, that lawtech usage does not differ significantly by year of qualification, according to the Oxford LawTech Survey. ${ }^{79}$

From the educational provider's perspective, the question is both which institutions could satisfy the demand and how they should do so. The limitations of education run internally was shortly discussed above. Interestingly, the Oxford LawTech Survey revealed that the most popular was 'training provided by an external provider' (50 per cent ranked this No.1), followed by 'training delivered in-house by my employer' ( 29 per cent ranked this No.1) and 'self-directed (or self-service) training' (22 per cent ranked this No.1) ${ }^{80}$ This aligns with the results from our interviews. This data, however, does not consider the specific learning needs of Legal Technologists.

The educational methods mentioned by our interviewees ranged from lunchtime talks, drop-in sessions, half-day seminars, conference attendances, online courses and webinars, degree-level education, placements, to experiential 'hands-on' workshops (including hackathons) led by internal or external instructors. Should there at any point be a full Legal Technologist qualification, some mixture of these methods would be undoubtedly useful. Importantly, our course experimentation confirms the importance of project teamwork. Thanks to the 'Law and Computer Science' course, we discovered that the practical project was at least as important as the theoretical sessions in this respect, probably more so. Thus, one law student told us that: ' $t$ ] he best aspect of the interdisciplinary course work with the peers from my cohort is the practical project. This project exposed me to why and how law ... and computer science should collaborate in developing emerging technologies. For instance, in the course of the project, the lawyers on the team consistently assess some of the technical solutions proposed by the computer science students and how it will fit into the legal framework with less friction'. We also

\footnotetext{
${ }^{76}$ 'City law firm 5' interview, similarly 'City law firm 1' interview and 'City law firm 4' interview.

77 'Global lawtech firm' interview.

${ }^{78}$ See also 'Medium UK lawtech firm 2' interview.

${ }^{79}$ Sako, Armour and Parnham (n 3$) 5$ and 6.

${ }^{80}$ Ibid 11.
} 
found that this practical aspect of the course helped to develop our students' mental agility, their design thinking and commercial awareness. The new SQE may potentially open new learning paths too, but it is, of course, still too early to tell. In general, whatever form they ultimately take, the qualifications enabling someone to become a Legal Technologist seem more fit for graduate-level qualification (either part-time or full time) for students with preferable background in law or computer science. From an educational viewpoint, there is no particular reason to run a course for Legal Technologists either online or offline, though as we have all seen, other factors can effectively make that decision.

This relates to the fourth perspective, which is of the individual educator. We submit that each of the five areas of learning need for Legal Technologists could be instructed by a different combination of educators, but all these areas would benefit from some collaboration between universities, who would provide the theoretical backing and educational expertise, and law firms, tech firms, hypothetical clients, investors, startuppers and non-governmental digital policy makers. At this stage, the sector seems to be moving so fast that academics and professionals cannot afford not to collaborate if they want to succeed. Our interviews suggest that law professionals feel there is a gap between what is beneficial for the sector and what universities currently offer from an educational viewpoint. ${ }^{81}$ Interestingly, one responded stated that 'some law firms see it as part of their social contract to train people up. Others (and historically this was a perception of some US firms' approach to junior lawyers particularly) adopt a different model of not taking on trainees, just paying top dollar and taking good people once someone else has trained them' ${ }^{82}$ And yet in fact, as we have examined elsewhere, the more academic approach of a university, with its focus on critical, normative assessment as well as the acquisition of knowledge, may in fact provide precisely the holistic, problem-solving, systems view that is required. And, of course, universities' inherently interdisciplinary nature also makes them perfectly suited to provide that aspect of the necessary training. ${ }^{83}$

Finally, there is a broader national perspective. How should Legal Technologists' education and training be supported by national organisations such as The Law Society, The Bar Council, Society of Legal Scholars, various research councils, Tech Nation, and the Department of Education? Surely, if Legal Technologists' learning needs were to become a recognised standard and were to be support for the learning models and collaborative educational providers outlined here, then national bodies will be more easily able to target those providers with the financial and media support that would accelerate the necessary course development, placements programmes, experiential learning, and scholarships for students-even if Legal Technologists were to be educated on non-degree programmes. At the same time, some members of these national bodies will inevitably want to join the educational providers on advisory boards for the proposed Legal Technologist courses.

\section{CONCLUSIONS}

Our research seems to confirm the hypothesis that the provision of tech-enhanced legal services is partly limited by skills and knowledge gaps amongst legal service providers. What kind of education will thus help lawyers to provide tech-enhanced legal services?

\footnotetext{
${ }^{81}$ eg, 'Global law firm' interview, 'Large UK law firm 1' interview, 'Large UK law firm 2' interview.

82 'Global law firm' interview.

${ }^{83}$ See Williams, Janeček and Keep (n 7).
} 
This paper argued that a common core of lawtech skills and knowledge are particularly important to meet the learning needs in the sector. In particular, five core areas of learning needs emerged from our research: 1) Mindset understanding; 2) Dataoriented thinking; 3) Agile systems and design thinking; 4) Commercial awareness; 5) Digital ethics and the law relating to AI and digital technology. These areas seem to be jointly significant for the provision of tech-enhanced legal services and could be thus embodied into a Legal Technologist qualification. They may also serve as a blueprint for multidisciplinary team assembly. In many respects, these learning needs mirror trends towards $21^{\text {st }}$ century skills that we see in other professions.

We argued that knowledge and skills that fall into these five areas are transferable and can provide the required stability and credibility in the legal market. As such, it might be expected that these skills and knowledge capabilities will be increasingly demanded by the legal sector. At this stage, it is unclear whether these learning needs should be satisfied by a degree-level education. Given that lawtech is now quickly evolving, we argued that educational and training programmes in this area would benefit from collaboration between university educational experts and professionals from the lawtech sector. Backing from national bodies would also be desirable.

Our research also revealed several specific learning needs which, in our view, should be seen as a continuous and continuously changing demand that could be satisfied primarily through CPD or ExecEd programmes. This is mainly because those needs are relative to technologies and roles, and because these needs are therefore often only temporary.

Given that tech-enhanced legal services will likely play an important role in the future of legal services, we hope our research-led suggestions will be a welcome contribution to the debate on the future of legal education more generally. If there is a right time to bring up a generation of Legal Technologists who will help us to navigate through the uncertain digital waters of the $21^{\text {st }}$ century whilst protecting the worth of legal services, it is probably now. 